\title{
A non-invasive test for receptor binding applied to nephrogenic diabetes insipidus
}

\author{
K. E. BRITTON \\ M.D., M.Sc., M.R.C.P. \\ A. M. KHOKHAR \\ B.Sc., M.B., B.S., M.R.C.P., Ph.D.
}

\author{
R. S. TEDDER \\ M.A., M.B., B.Chir., M.R.C.P. \\ N. J. G. Brown \\ M.A.
}
J. D. H. SLATER
F.R.C.P.
J. D. H. SLATER
F.R.C.P.

\author{
A. Davison \\ S.R.N.
}

Department of Nuclear Medicine and the Cobbold Laboratories, Institute of Clinical Science, The Middlesex Hospital, London

\begin{abstract}
Summary
Studies in animals have determined the importance of specific receptors to the action of many hormones and drugs. In man, a non-invasive external counting technique has been used and absence of receptor function has been demonstrated in a patient with nephrogenic diabetes insipidus using radioactively labelled arginine vasopressin. This is in contrast to the findings in a patient with pituitary diabetes insipidus and a normal control. These results suggest a model for the study of hormone and drug kinetics in man avoiding multiple samplings of biological fluids.
\end{abstract}

\section{Introduction}

A necessary feature of hormone and often of drug action is the presence of specific receptors in the target tissue. Such tissue receptors are commonly investigated by determining their binding characteristics in vitro or in experimental animals by the use of a radionuclide-labelled analogue of the relevant biologically active compound, the ligand (Cuatrecasas 1974a, b). The authors suggest that this approach can be extended to man with the use of computer-assisted external counting techniques designed to measure the uptake or lack of uptake of the radionuclide-labelled ligand by the target tissue. This non-invasive approach is applicable both to normal people and to those with disease and avoids the possible lack of representativeness of an animal model.

To test this idea, the authors studied the pattern of ${ }^{125} \mathrm{I}$-arginine vasopressin (AVP) binding by the kidney. Campbell, Woodward and Borberg (1972) showed the presence of specific ADH receptors in normal porcine kidney tissue and Nardacci, Mukho-

Correspondence: Dr K. E. Britton, Department of Radioisotopes and Nuclear Medicine, St Bartholomew's Hospital, West Smithfield, London EC1A 7BE. padhyay and Campbell (1975) showed that the receptor site was closely associated with a peptidase capable of degrading AVP. The dynamics of the renal uptake of ${ }^{131}$ I-AVP have therefore been compared in a man with pituitary diabetes insipidus, a man with nephrogenic diabetes insipidus, a well established entity (Dicker and Eggleton, 1963) and a normal control (R.S.T.).

\section{Radionuclide techniques}

${ }^{131}$ I-AVP, free of ${ }^{131} \mathrm{I}$ is prepared as previously described by Khokhar, Ramage and Slater (1975) but ${ }^{131} \mathrm{I}$ is substituted for ${ }^{125} \mathrm{I}$. The external counting technique is performed exactly as for analogue computer-assisted blood background subtraction 131I-hippuran (sodium iodohippurate) renography (Britton and Brown, 1971). In addition to setting up a detector over each kidney region, a third detector is placed over a non-kidney region, the right chest. The record from this detector enables one to correct the composite ${ }^{131} I-A V P$ renogram for ${ }^{131} I-A V P$ present in the renal environment so as to demonstrate clearly the uptake of ${ }^{131}$ I-AVP by the kidney itself. To compensate for the different volumes of tissue viewed by the three detectors, $10 \mu \mathrm{Ci}{ }^{131}$ I radioiodinated human serum albumin (Radiochemical Centre, Amersham) is injected first and recordings are made for $5 \mathrm{~min}$ to obtain the necessary correction factors (Britton and Brown, 1971). Then $25 \mu \mathrm{Ci}{ }^{131} \mathrm{I}-\mathrm{AVP}$ containing about $20 \mu \mathrm{u}$. (50 pg) are injected and records are made for up to $20 \mathrm{~min}$ of the automatically derived kidney ${ }^{131} \mathrm{I}$-AVP.

The results are presented in the form of activity/ time curves of ${ }^{131} \mathrm{I}$-AVP in the kidneys and in the chest against time (Figs 1, 2 and 4). Correction for the effect of ${ }^{131} I-A V P$ in the non-renal environment in the field of the kidney region detector, is essential to measure accurately the relatively low uptake by 
the kidneys of ${ }^{131} \mathrm{I}-\mathrm{AVP}$, for example, compared with ${ }^{131}$ I-sodium iodohippurate.

\section{Patients}

(1) A 38-year-old Pakistani man first recollected symptoms suggestive of diabetes insipidus about the age of 8 years. In 1966 he moved to England where investigations showed that there was no renal response to injection or nasal inhalation of posterior pituitary extract or synthetic lysine vasopressin. A maternal grandmother suffered from marked thirst and polyuria. The patient was passing 10-12 1 of urine $/ 24 \mathrm{hr}$ which was reduced by bendrofluazide (10 mg nocte) to 4-6 1/24 hr. The urine was sterile and the endogenous creatinine clearance $(111 \mathrm{ml} /$ min) and urine amino acid chromatogram were normal. Deprivation of water for $12 \mathrm{hr}$ caused a $6.7 \%$ loss of body-weight and, despite a ten-fold rise in urinary AVP (16-20 $\mathrm{pg} \mathrm{ml}^{-1}$ dehydrated, rising to $156 \mathrm{pg} \mathrm{ml}^{-1}$ at the end of $12 \mathrm{hr}$ ), the urine osmolarity remained between 60 and $80 \mathrm{mosmol} / \mathrm{kg}$. Infusion of either lysine vasopressin or arginine vasopressin failed to change urine osmolality. In addition there was no increase of plasma or urine cyclic adenosine monophosphate concentration. These findings strongly support a diagnosis of nephrogenic diabetes insipidus.

(2) A 47-year-old Ukranian had a 5-year history of increasing polyuria. He was passing between 10 and 141 of urine per $24 \mathrm{hr}$. The urine was sterile and the endogenous creatinine clearance $(110 \mathrm{ml} / \mathrm{min})$ and urine acidification test were normal. Deprivation of water for $24 \mathrm{hr}$ caused a fall in body-weight of $3.2 \mathrm{~kg}(4.5 \%)$. Despite a rise of plasma osmolality from 275 to $283 \mathrm{mosmol} / \mathrm{kg}$ the maximum urine osmolality achieved was $428 \mathrm{mosmol} / \mathrm{kg}$. However, with a liberal water intake and the intramuscular injection of 5 units of lysine vasopressin (Parke Davis), the urine osmolality increased to 558 mosmol/ $\mathrm{kg}$ and restored $1.8 \mathrm{~kg}$ body-weight in the next hour. He is symptom free with use of an AVP spray (Syntopressin Parke Davis) four times daily, which reduced his urine output from 12 to 31 per hour.

(3) A 23-year-old author of the present report (R.S.T) in good health was chosen as a normal control.

\section{Results}

Figure 1 shows the result obtained in the normal control. There are three phases: an initial rapid rise followed by a slower rise to peak at about $7 \mathrm{~min}$, followed by a third phase of falling activity. From the rising phase of this activity/time curve, the distribution of the uptake of the injected bolus of ${ }^{131} \mathrm{I}$ AVP is calculated to have a time constant of about $3 \mathrm{~min}$ as it is received as input by the kidney. The falling third phase is due to continuing lower level of

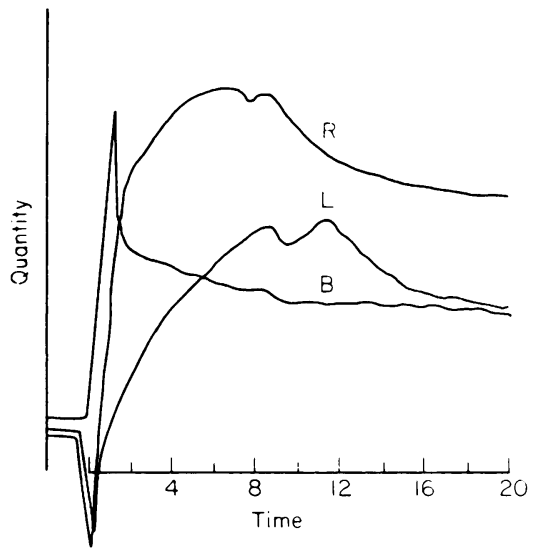

FIG. 1. Kidney uptake curves of ${ }^{131}$ I-AVP traced from the original chart recordings, right $(R)$ and left $(L)$. The non-renal tissue activity/time curve is recorded over the chest (B). Results obtained in the normal control. (Quantity in arbitrary units of activity: time in min.)

input as shown by the tissue clearance curve recorded over the chest; together with a removal component comprising loss of ${ }^{131} \mathrm{I}$-AVP in urine both unchanged and as free ${ }^{131} \mathrm{I}$ from degradation of 131I-AVP.

Figure 2 shows the activity/time curves of ${ }^{131}$ IAVP, obtained from the same batch preparation as the control, in the patient with nephrogenic diabetes insipidus. Apart from the 'injection artefact' at the start of the kidney curves, the traces demonstrate no significant uptake of ${ }^{131}$ I-AVP. This confirms the absence of a functioning receptor for ${ }^{131}$ I-AVP. The lack of rise and fall of the curve would also indicate that the amount of ${ }^{131}$ I-AVP taken up by the kidney

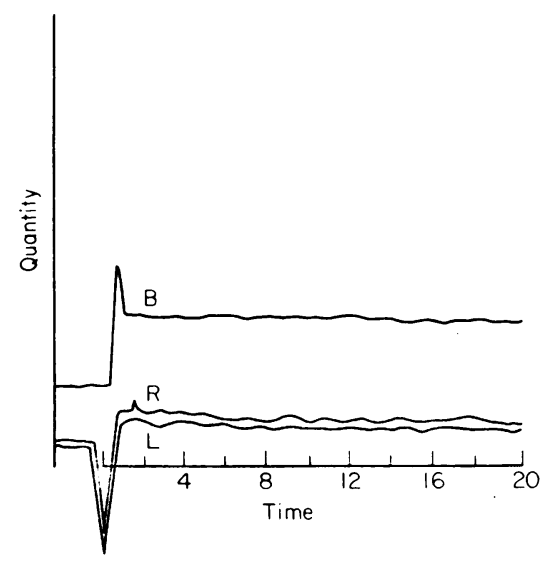

FIg. 2. The kidney uptake curves of ${ }^{131} I-A V P$ in the patient with nephrogenic diabetes insipidus. No uptake is seen (key as for Fig. 1). 
due to passive processes such as glomerular filtration must be very small. This would imply that at physiological plasma concentrations, ${ }^{131} \mathrm{I}-\mathrm{AVP}$ is weakly associated with a larger molecule in the blood (Lauson, 1974) and that the falling third phase of the ${ }^{131}$ I-AVP activity/time curve of the normal control would most likely be due to free ${ }^{131}$ I after ${ }^{131}$ I-AVP degradation. That the kidney function was indeed normal in the patient with nephrogenic diabetes insipidus is indicated by the normal ${ }^{131}$ I sodium iodohippurate kidney curves shown in Fig. 3. Figure 4 shows the ${ }^{131}$ I-AVP activity/time curves in the patient with pituitary diabetes insipidus. It differs little from the result in the normal control (Fig. 1) except that the third phases fall much more slowly.

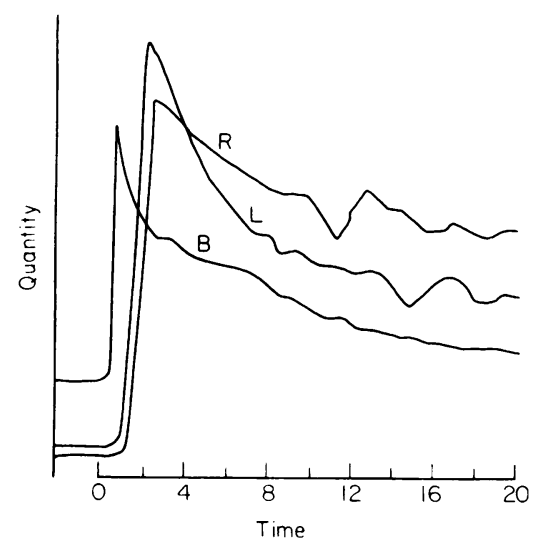

FIG. 3. The kidney uptake curves of ${ }^{131}$ I-sodium iodohippurate in the patient with nephrogenic diabetes insipidus. Normal uptake is seen (key as for Fig. 1).

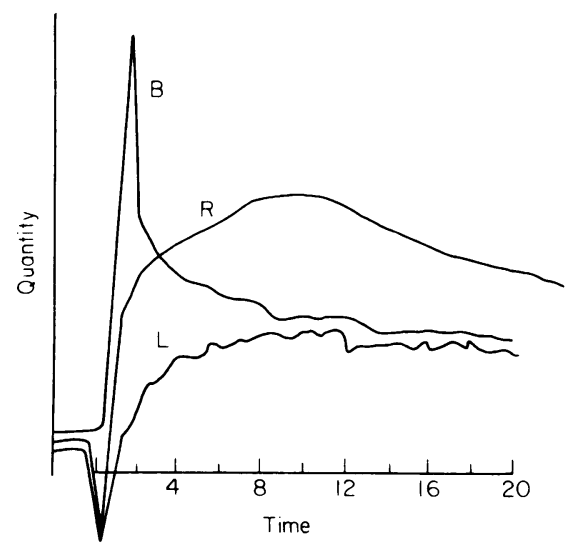

FIG. 4. The kidney uptake curves of ${ }^{131} I$-AVP in the patient with pituitary diabetes insipidus. Normal uptake is seen but the rate of fall of activity after the peak is diminished compared with the normal control (key as for Fig. 1).

\section{Discussion}

The results demonstrate that an analogue of the antidiuretic hormone, ${ }^{131} \mathrm{I}-\mathrm{AVP}$, is not taken up by the normal kidneys of a patient with nephrogenic diabetes insipidus, whereas a normal control and a patient with pituitary diabetes insipidus demonstrate considerable uptake. This indicates a failure or absence of functionally active receptors for vasopressin in the kidney in nephrogenic diabetes insipidus.

It is unlikely that this lack of uptake is just due to dilution of the injected ${ }^{131}$ I-AVP by circulating AVP since about $10 \%$ of the injected ${ }^{131} \mathrm{I}-\mathrm{AVP}$ goes directly to each kidney with the first circulation as each receives that fraction of the cardiac output. It is possible that all receptor sites for AVP were fully occupied in the patient with nephrogenic diabetes insipidus. This is unlikely because the rate of renal AVP excretion at the time of the study was appropriate for his state of hydration; it was equal to or less than the value seen in normal young men in a similar state of hydration (Khokhar, Ramage and Slater, 1975).

The slower removal rate for ${ }^{131}$ I-AVP from the kidneys of the patient with pituitary diabetes insipidus as compared with the normal control suggests that the level of enzyme in the degradation of AVP is reduced in pituitary diabetes insipidus. The greater amplitude of the right kidney ${ }^{131}$ I-AVP curve as compared with the left might imply additional liver uptake. This technique may be applicable as a diagnostic aid both in congenital nephrogenic diabetes insipidus and also in acquired forms, for example, amyloidosis (Carone and Epstein, 1960), or sarcoidosis (Panitz and Shinaberger, 1965), or in post-obstructive diuresis to which $\mathrm{ADH}$ unresponsiveness probably contributes.

This study was undertaken to draw attention to the idea that by a non-invasive technique in man, it is possible to assess end-organ receptor responsiveness to biologically important compounds as a way of complementing biochemical studies. With the appropriate choice of labelled hormone, the technique may be of use in the investigation of testicular feminization (French et al., 1965) and pseudohyperparathyroidism (Albright et al., 1942). In particular, external counting techniques may allow an approach to pharmacokinetics in man that is more direct but complementary to studies which rely on multiple sampling of drug levels in biological fluids.

\section{References}

Albright, F., Burnett, C.H., Smith, P.H. \& Parson, W. (1942) Pseudohyperparathyroidism - an example of Seabright Bantam Syndrome. Endocrinology, 30, 922.

BritTON, K.E. \& BROWN, N.J.G. (1971) Clinical Renography. Lloyd-Luke, London. 
Campbell, B.J., Woodward, G. \& Borberg, V. (1972) Calcium mediated interactions between the antidiuretic hormone and renal plasma membranes. Journal of Biological Chemistry, 247, 6167.

CARONE, F.A. \& EPSTEIN, F.H. (1960) Nephrogenic diabetes insipidus caused by amyloid disease. American Journal of Medicine, 29, 539.

Cuatrecasas, P. (1974a) Problems in receptor identification: catecholamines. New England Journal of Medicine, 291. 206.

Cuatrecasas, P. (1974b) Membrane receptors. Annual Review of Biochemistry, 43, 169.

Dicker, S.E. \& Eggleton, M.G. (1963) Nephrogenic diabetes insipidus. Clinical Science, 24, 81.

French, F.S., Baggett, B., VAN WyK, J.J., TAlbert, L.M., Hubbard, W.R., Johnston, F.R. \& Weaver, R.P. (1965)
Testicular feminisation. Journal of Clinical Endocrinology, 25, 661 .

Khokhar, A.M., Ramage, C.M. \& Slater, J.D.H. (1975) Radioimmunoassay of arginine vasopressin in urine. Journal of Endocrinology, 67, 66.

LAUSON, H.D. (1974) Metabolism of neurohypophysical hormones. In: Handbook of Physiology-Endocrinology IV, Part 1, p. 296. American Physiological Society, Washington.

Nardacci, N.J., Mukhopadhyay, S. \& Campbell, B.J. (1975) Partial purification and characterisation of the antidiuretic hormone inactivating enzyme from renal plasma membranes. Biochimica et biophysica acta, 377, 146.

Panitz, F. \& Shinaberger, J.H. (1965) Nephrogenic diabetes inspidus due to sarcoidosis without hypercalcaemia. Annals of Internal Medicine, 62, 113. 